\title{
Reactions of selectively bred strains of rats to a cat
}

\author{
K. PAUL SATINDER \\ Lakehead University, Thunder Bay, Ontario, Canada P7B 5El
}

\begin{abstract}
Reactions of five strains of rat to a cat, a rabbit, and a box, all of comparable size and color, were investigated. The response measures were approach behavior score, general activity, percentage of activity in the neighborhood of the stimulus objects, rearing, defecation, latency to emerge, direction of emergence, and freezing and touching the stimulus objects. Rats avoided the cat, froze in the presence of the cat, and showed higher levels of emotional reactivity to the cat than to the rabbit or the box. The five strains of rat were more uniform in their reactions to the cat than to the rabbit or the box.
\end{abstract}

In an experimental study of defensive reactions, Blanchard and Blanchard (1971) were able to demonstrate that an approaching cat elicited active avoidance in albino rats, that rats crossed an electrified grid to avoid an immobile cat, and that when confined with a cat the rats' predominant response was freezing. In a subsequent investigation, Blanchard and Blanchard (1972) demonstrated that when inescapably confronted by a cat, rats with hippocampal lesions displayed lower levels of freezing than did operated controls. When, however, avoidance or escape was possible, rats with lesions showed a higher level of cat avoidance and less freezing.

It is a fact, however, that in the process of domestication, more specifically in the process of laboratorization (Robinson, 1965), rats almost never come in contact with a cat (one of the natural predators). Hence, there remains a possibility that the findings reported by Blanchard and Blanchard $(1971,1972)$ are specific to the strain of rats used and reflect the reactions of rats to a strange object rather than to the presence of a cat. As the authors themselves point out, "these results alone do not indicate that freezing and active avoidance are elicited only by a cat or only by predators of the rat" (Blanchard \& Blanchard, 1971 , p. 361). For these reasons, the present investigation was under taken to study, with additional controls, the reactions of various strains of rats to a cat. As Boice (1973) noted, selection plays a critical role in the laboratorization of animals;

This research was partially supported by an operating research grant, AO321, from the National Research Council of Canada to the author. The author expresses his thanks to Robert $A$. McGowan for his help in conducting the experiment. A preliminary draft of this paper was presented at the Behavior Genetics Association meetıng in June 1974. Comments on an earlier version of the paper by Drs. S. A. Barnett, R. J. Blanchard, and R. Boice are highly appreciated. Requests for reprints should be sent to K. Paul Satınder, Department of Psychology Lakehead University, Thunder Bay, Ontario, Canada, P7B 5E] therefore strains of rats selectively bred for behaviors related to defense reactions were used.

Among the five strains of rats, two were Maudsley nonreactive (MNR) and reactive (MR), established by selective breeding for low and high defecation score in an open-field test of emotional reactivity by Broadhurst (1960) and designated as such by Jay (1963). Two other strains were those developed by Bignami (1965) for high and low rates of two-way active avoidance conditioning and designated by Broadhurst and Bignami (1965) as Roman highavoidance (RHA) and Roman low-avoidance (RLA) conditioning strains, respectively. The fifth strain was random bred from the same stock of animals as the parental generation of the RHA and RLA strains and designated as Roman control avoidance (RCA). These strains have been redesignated as $\mathrm{MNR} / \mathrm{Har} / \mathrm{Lu}, \mathrm{MR} / \mathrm{Har} / \mathrm{Lu}, \mathrm{RHA} / \mathrm{Lu}, \mathrm{RLA} / \mathrm{Lu}$, and $\mathrm{RCA} / \mathrm{Lu}$, further details of which have been reported in Satinder $(1971,1972)$.

\section{METHOD}

\section{Experimental Design}

As pointed out earlier, previous findings (Blanchard \& Blanchard, 1971, 1972) could be attributed to the presence of a strange object rather than a cat per se. Furthermore, a strange object could be either a potential predator or a nonpredator, and a nonpredator object could be etther anımate or inanimate. Hence, to provide appropriate controls, a cat, a rabbit, and a box, all of a comparable size and black in color, were used as stimulus objects. The cat was procured from the local Humane Society, and the rabbit was on loan from a local rabbit breeder.

\footnotetext{
Subjects

One hundred and fifty 200-day-old experimentally naive rats, equally represented by five strains and both sexes, were used as subjects. The strains were: $\mathrm{MNR} / \mathrm{Har} / \mathrm{Lu}, \mathrm{S}_{45}$; $\mathrm{MR} / \mathrm{Har} / \mathrm{Lu}, \mathrm{S}_{39-40} ; \mathrm{RCA} / \mathrm{Lu}, \mathrm{S}_{25} ; \mathrm{RHA} / \mathrm{Lu}, \mathrm{S}_{25}$; and RLA/Lu, $S_{25}$. All the animals were bred and reared in the laboratory and weaned at 28 days. Before experimentation, the animals were housed in same-sex pairs, with the strains on separate cage racks. The animals were not handled from weaning until experımentation started except for regular maintenance (Satinder \& Hill, 1974) None had had pror exposure to the stimulus
} 
Table 1

Means and Frequencies of Responses

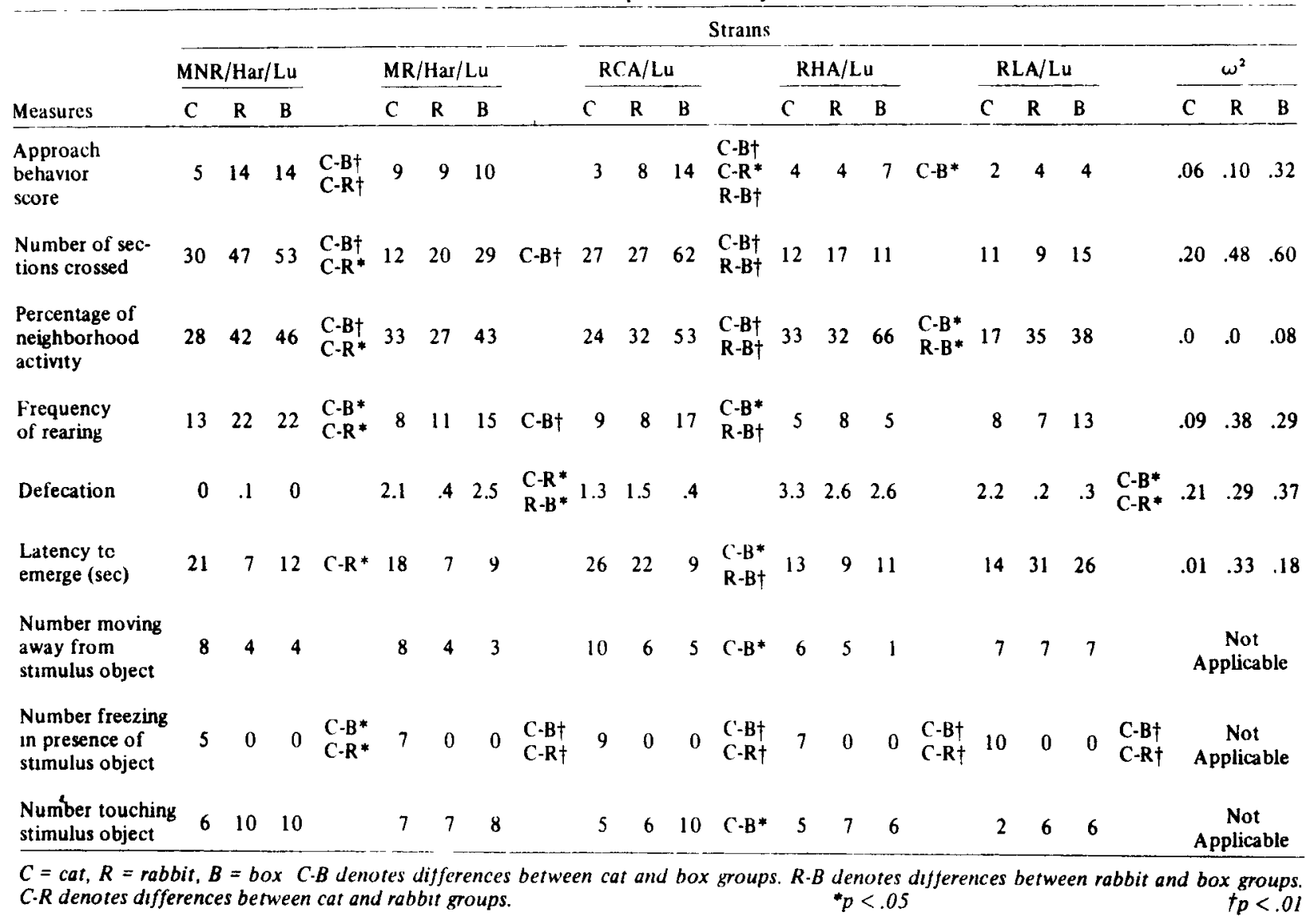

objects. During experimentation, the animals were coded and housed individually, the laboratory temperature was thermostatically controlled at $72^{\circ} \pm 2^{\circ} \mathrm{F}$, and the humidity level was maintained at $40 \%$. Fluorescent lights were on from 9:00 a.m. to $9: 00$ p.m.

\begin{abstract}
Apparatus
An open-field arena, $90 \mathrm{~cm}$ on each side and divided into 16 equal-area square sections marked on the floor, was used. The arena was made of plywood and white melamine plastic, and the walls were $45 \mathrm{~cm}$ high. The front wall was a sliding door of transparent Plexiglas, which served as an observation screen and as a door for cleaning the arena. The arena was lighted by four $90-\mathrm{cm}$-long fluorescent lights, $90 \mathrm{~cm}$ above the floor level, which provided an illumination of $230 \mathrm{fc}$ at the floor center of the arena.
\end{abstract}

\section{Procedure}

The cat and the rabbit were adapted, through several 1-2-h familiarization sessions, to sit inactively in a corner facing the center of the arena. They were also given several habituation sessions with other rats before they encountered the experimental rats. The experimental rats were randomly divided, from each of the strains and sexes, into three groups of 50 each, which were exposed to the cat, the rabbit, and the box, respectively. The animals were individually exposed under a Plexiglas container near and facing the stimulus object. All the animals and stimulus objects were exposed at exactly the same place and position. The container covering the animal was lifted immediately after the animal faced the stımulus object, and a timer was started simultaneously. The following response measures were taken during a 5-min trial. Time taken to emerge from the square in which the animal was exposed was designated as latency to emerge. The direction of emergence was also recorded: if the animal emerged by moving away from the stimulus object, a value of 1 was assigned; if it moved toward the stimulus object, a value of 0 was assigned. Approach behavior toward the stimulus object was defined and scored as follows: approach (assigned value 1), the animal moved toward the stimulus object without touching it; touch (assigned value 2), the animal approached and touched the stimulus object. The number of sections crossed during the trial was recorded and defined as a measure of general activity. The percentage of sections crossed in the half of the arena containing the stimulus object was calculated and designated as neighborhood activity. The number of defecations and frequency of rearing were also recorded. If the animal remained motionless for at least $1 \mathrm{~min}$ at one time, freezing behavior was recorded and assigned a score of 1 ; the absence of freezing behavior was scored as 0 . The open field was cleaned after each trial.

\section{RESULTS}

The means and frequencies of occurrence of the various responses were calculated and are presented in Table 1 according to strains and experimental groups. The results were evaluated by analysis of variance and chi square. To account for the variance attributable to strain differences, $\omega^{2}$ values were calculated (Hays, 1963, p. 382, where J represents the number of genotypes) and are presented in Table 1. 
In general, the rats reacted the most to the cat, followed by the rabbit and the box. The differences among the experimental groups showed that the rats exposed to the cat had the lowest approach behavior score $(\mathrm{F}=9.65, \mathrm{df}=2 / 120, \mathrm{p}<.001)$, crossed the least number of sections $(\mathrm{p}<.001)$, were least active in the stimulus neighborhood $(p<.001)$, reared least $(p<.005)$, had the highest defecation score $(p<.025)$, took the longest time to emerge $(\mathrm{p}<.05)$, avolded the cat most by moving away at emergence $\left(\chi^{2}=16.71, \mathrm{df}=2, p<.001\right)$, showed maximum freezing behavior $(p<.001)$, and touched the cat the least $(p<.01)$. The box group had $490 \%$ of its activity in the neighborhood of the stimulus object, and none of the strains differed significantly from the expected $50 \%$ activity in the neighborhood area. The rabbit group in general had $34 \%$ of its activity in the neighborhood, and the $\mathrm{MR} / \mathrm{Har} / \mathrm{Lu}(\mathrm{p}<.01)$ and the RHA/Lu $(p<.05)$ strains were significantly less active in the neighborhood. The cat group animals had $27 \%$ of their actuvity in the neighborhood, and the MNR/Har Lu, RCA/Lu, and RLA/Lu strains had sgnificantly less activity in the neighborhood $(0<.01)$. In general, there were significant differences between the cat and box groups on all the response measures except latency to emerge, and between cat and rabbit groups on all measures except latency to emerge, percentage of neighborhood activity, and number of sections crossed. However, between rabbit and box groups, the differences were significant only in the number of sections crossed and neighborhood activity. The significant differences between thic experirnental groups in all the strains are indicated $n$ Table 1 for all the response measures.

There were significant differences among the strains in approach behavior score $(F=7.09$, df $:=4 / 120$, $p<.005)$, number of sections crossed $(p<.001)$, trequency of rearing $(\mathrm{p}<.001)$, defecation score $(p<.005)$, latency to emerge $(p<.005)$, and number of animals touching the stimulus objects $(p<.02)$, but these differences were of varying magnitude in the experimental groups (refer to $\omega^{2}$ values in Table 1). There were significant interactions between strains and experimental groups in the number of secions crossed $(p<.005)$, frequency of rearing $(p<.05$ ), defecation score $(p<.025)$, and latency to emerge $(p<.005)$.

In general, females showed significantly higher approach behavior $(p<.003$ ), crossed a higher number of sections $(p<.05)$, had a higher frequen cy of rearing $(p<.005)$, defecated less $(p<.025)$, and took less time to emerge $(p<.025)$ than males. There were significant interactions between sex and experimental groups on approach behavior score $(p<.006)$ and defecation score $(p<.05)$.

The comparison between Maudsley reactive and nonreactive strains showed observable differences (Table 1) in approach behavior scorc, especially in the cat groups. Further differences between these two strains were also noticeable in number of sections crossed, frequency of rearing, and defecation. The differences between the Roman high- and lowavoidance conditioning strains were noticeable (Table 1) in defecation score, latency to emerge, and number of animals moving away from the stimulus objects.

Correlations were calculated between the various response measures based on the scores of the rats of all the five strains exposed to the cat and are presented in Table 2.

It can be observed (Table 2) that significant correlations form basically two distinct sets. One set of correlations includes approach behavior, sections crossed. neighborhood activity, and frequency of rearing. All the significant correlations are positively related with each other. The other set of significant correlations includes all the behavioral measures in which the first four measures listed in Table 2 are negatively correlated with those measures listed from 5 to 8 in Table 2 .

The correlations were also calculated according to strains and experimental conditions, separately and combined. In the MNR/Har/Lu and RHA/Lu strains, significant correlations occurred between different response measures in the three experimental conditions. In the $\mathrm{MR} / \mathrm{Har} / \mathrm{Lu}$ and $\mathrm{RLA} / \mathrm{Lu}$ strains, the same response measures showed significant correlations in three conditions. In the RCA/Lu

Table 2

Correlation Matrix of Responses of Rats to a Cat

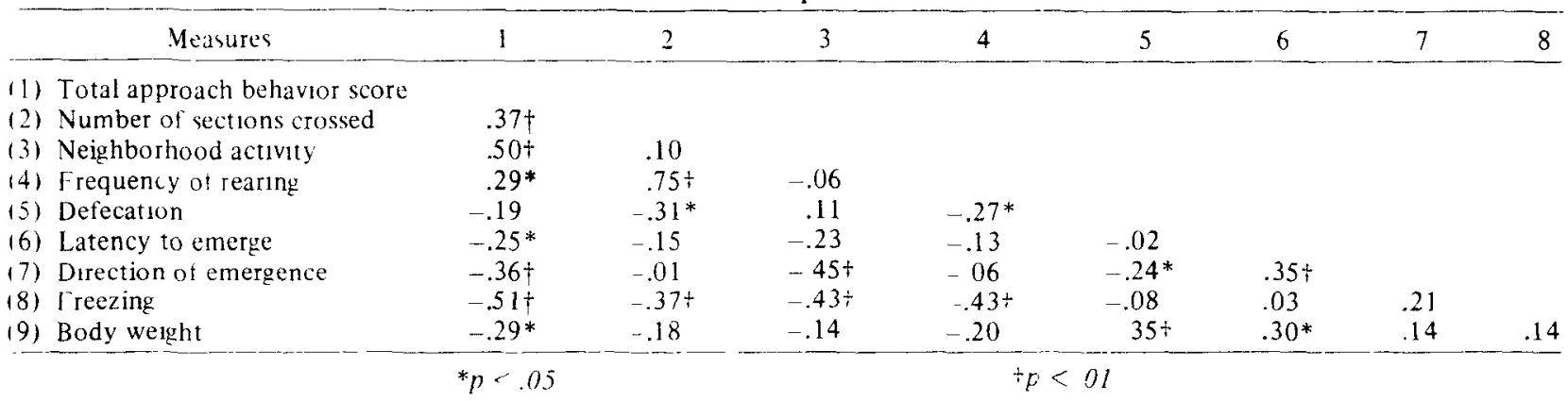


strain, the correlations which were not significant in one condition became significant in the opposite direction in other experimental conditions.

\section{DISCUSSION}

These findings indicate that rats do respond differentially to the presence of an animate or inanimate object and to a potential predator or a nonpredator animal, although some of these responses are genotype-specific. Irrespective of the strain, differences were found between the cat and box groups and the cat and rabbit groups on more measures than between the rabbit and box groups, as indicated earlier. The $\omega^{2}$ values (Table 1) in the cat group are of much lower magnitude than those of the rabbit and box groups, suggesting that between-strain variation was considerably reduced in the cat group. This tends to show that the stronger the fear stimulus, the less the difference among strains. These findings indicate three distinct reactions of rats to the presence of the cat in the immediate environment. First, rats exposed to the cat avoided more frequently than the rats exposed to the rabbit and the box as stimulus objects. Avoidance behavior in response to the presence of the cat is indicated by a lower approach behavior score, lower neighborhood activity, and a higher frequency of the direction of emergence away from the cat. Second, rats exposed to the cat showed a higher incidence of freezing behavior, represented by lower levels of activity and rearing, longer latency to emerge, and higher levels of motionless state. Third, rats showed a higher level of emotional reactivity (defecation) in the presence of the cat. These reactions are clearly depicted by the correlations reported in Table 2 and may be summed up as an increase in generalized freezing.

These findings extend those of Blanchard and Blanchard (1971), showing that rats do respond differentially to the presence of a cat, "suggesting that active avoidance of $a$ cat is indeed a motivated reaction, even if the rat has had no experience with cats" (p. 360). An additional contribution of the present findings to those of Blanchard and Blanchard (1971) is that the reactions of rats to a cat show evidence for a substantial commonality of reactions across rat strains. The present findings also indicate that possibly Blanchard and Blanchard's $(1971,1972)$ results were confounded by the fact that they did not include a control group to account for the presence of a strange object, since the RCA/Lu strain, which is random-bred Wistar-derived and closest to the rats used by Blanchard and Blanchard, did not really differentiate between the cat and the rabbit except in freezing behavior (Table 1).
Some of the strain-specific reactions of rats to the present stimuli would tend to suggest that probably factors involved in genetic selection play an important role. This is suggested by the following: (1) The largest number of significant differences showing avoidance and freezing were found between the experimental conditions only in the RCA/Lu strain (Table 1), a random-bred albino rat. This may sugget that, in the absence of any specific genetic selection, this strain of rat has not shown much change in the laboratorization process and possibly represents the least genetic drift from a natural population for the strains investigated in the present study. Note, in this context, that among animals in natural settings, the avoidance of strange objects and especially of strange animals of other species is common (Barnett, 1963). Our experience shows that, even when reared in the same conditions as the other four selectively bred strains, the RCA/Lu animals seem to be comparatively untamed; when handled, they struggle, bite, and squeal more frequently than do the animals of the other strains used in this investigation. Furthermore, a large number of the RCA/Lu animals showed fear or even panic behavior in the presence of the cat, whereas some of the animals from the other four strains engaged themselves in playful behavior with the cat. (2) The effects of the genetic selection are further illustrated by the observed differences between the $\mathrm{RCA} / \mathrm{Lu}$ strain and the RHA/Lu or RLA/Lu strains, because these three strains of rats had originated from the same stock of animals. Genetic selection has produced differences not only between the control and selected lines, but also between the bidirectionally selected lines. The only common reaction between the RHA/Lu and the RLA/Lu animals is in their freezing behavior; the other differences in the reactions of these strains, though minimal, are on different response measures (Table 1). However, the consistent and reliable differences found in the conditioned shock avoidance behavior of the high- and low-avoidance strains (Bignami, 1965; Satinder, 1971) have not been found in the unconditioned avoidance of cat between these two strains. In the MNR/Har/Lu strain, significant differences were observed, on six of the nine response measures, between the rabbit and the cat groups, indicating that the animals of this strain distinctly differentiated between the cat and the rabbit as well as between the cat and box, while in the $\mathrm{MR} / \mathrm{Har} / \mathrm{Lu}$ strain the differences between the experimental conditions were minimal and not attributable to any particular condition.

No specific attempt was made to examine the characteristics which produced the differential reactions of the rats to cat, rabbit, and box stimuli. A recent investigation (Blanchard, Mast, \& 
Blanchard, 1975), which was published after the completion of this research, found that neither the sound nor the smell of a cat, nor the sight of a dead cat, would produce freezing behavior $\mathrm{n}$ the rat, but that either a moving cat or dog or the abrupt or rapid movement of an inanimate object would produce freezing and a failure to approach the stimulus object. This suggests that movement is a major factor in the initiation of defensive reactions in the rat. As movement was not a variable in the present investigation, these findings cannot be explained in this context and exact mechanisms of these results still remain to be investigated.

\section{REFERENCES}

Barnetr. S. A. A stud in behavior Principles of ethology and behavioural psychology. displayed mainly in the rat. London: Methuen. 1963.

Bign 4MI. G. Selection tor high rates and low rates of avoidance condituoning in the rat. Animal Behaviour. 1965. 13. $221.22^{-}$

Blanchard, R J., \& Blanchard, D. C. Defensive reactions in the albino rat Learning and Motivation, 1971, 2. 351-362.

BLANCHARD. R. J., \& BLANChARD, D. C. Effects of hippocampal lesions on the rat's reactions to a cat. Journal of Comparative and Phistological Psychology. 1972, 78. 77-82.

Blanchard. R J.. Mast. M.. \& Blanchard. D. C. Stimulus control of detensise reactions in the albino rat Journal of Compurative and Physiological Psychology, 1975. 88. $81-88$.
Borce R Domesicatin Psichological Bull'tm. 1973, 80 . $215 \cdot 230$.

Broadhurst, P L Experiments in psychogenetics Application of bometrical genetics to behasiout In $H \mathrm{~J}$ Ersenck (Ed), Experments in persomalit) (Vol) 1) Psyehogentetcs and prichepharmacoleg: London. Routledge de Kegan Paul. 1960

Broadhl'rst, P L... \& Bignami G. Correlative effects of psychogenetic selection A study of the Roman high- and louavoidance strains of rats Behavior Research and Therapy, 1965, 2. 273-280

Hays, W. L. Stutistics. Neu York Holt. Rinehart and Winston. 1963.

JAY, G. E. Genetic strains and stocks In W. J. Burdette (Ed.). Methodology in mummalian genetics. San Francisco: Holden-Day, 1963

Robinson. R. Genetics of the Nomay rat Oxford: Pergamon Press. 1905.

SATINDER, K. P. Genotype-dependent effects of d-amphetamine sulphate and caffeine on escape-avoidance behavior of rats. Journal of Comparatw' and Physiological Psychology, 1971. 76. $359-364$

SATinder, K. P. Behavior-genetic-dependent selt-selection of alcohol in rats. Journal of Comparative and Physiological Psychology. 1972, 80, 422-434.

SATINDER, K P. \& Hill, K D. Effects of genotype and postnatal experience on activity, avoidance, shock threshold, and open-field behavior of rats. Journal of Comparative and Physiological Psychology, 1974, 86, 363-374

(Received for publication February 24, 1975; revision accepted October 21,1975 .) 